\title{
Ägyptische Erzählungen oder Über die Vorsehung
}

\author{
Hrsg. v. Martin Hose. Eingel., übers. u. m. interpretierenden Essays versehen v. \\ Martin Hose, Wolfgang Bernard, Frank Feder u. Monika Schuol
}

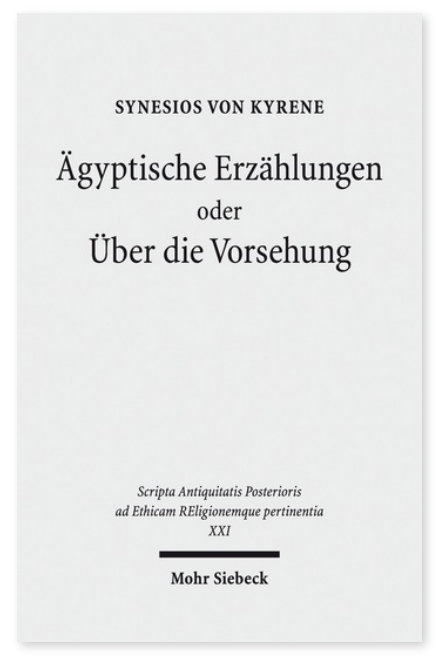

2012. X, 204 Seiten. SAPERE XXI

ISBN 978-3-16-156434-5

DOI 10.1628/978-3-16-156434-5 eBook PDF

ISBN 978-3-16-152259-8

fadengeheftete Broschur 29,00€
Synesios von Kyrene (ca. 370 -413 n. Chr.) darf als Repräsentant der spätantiken griechischen Oberschicht im Imperium Romanum gelten. Er studierte Philosophie in Athen und Alexandria, er bekleidete in Kyrene wichtige Ämter, unter anderem als Bischof, wie es für Angehörige der grundbesitzenden Eliten üblich war. Als Intellektueller stand er im Spannungsfeld zwischen Christentum einerseits und paganer literarischer Tradition (man könnte sie als »Kultur-Hellenismus« bezeichnen) und (neuplatonischer) Philosophie andererseits. Sein schriftstellerisches Oeuvre, Briefe, Hymnen und Traktate, zeigt seine produktive Auseinandersetzung mit dieser Spannung. In diesem Band wird mit den »Ägyptischen Erzählungen« ein Text des Synesios in deutscher Übersetzung (erstmals seit 1835) vorgelegt und durch Essays zur Zeitgeschichte, zur Form der Allegorie und zu ägyptischen Elementen erschlossen, in dem der Autor seine Erlebnisse während einer Gesandtschaft in

Konstantinopel am Kaiserhof mitteilt, die seiner Heimat eine Erleichterung der Steuerlast verschaffen sollte. Gewählt ist die Form einer allegorischen Erzählung, die Synesios als meisterhaften Literaten zeigt und den philosophisch überformten (ägyptischen) Osiris-Mythos mitteilt, in dessen Zentrum der Sturz des guten Regenten Osiris durch seinen finsteren Bruder Typhos steht. Neuplatonismus und »Ägyptische Weisheit« verschmelzen in der verrätselnden Form der Allegorie spätantiker Zeitgeschichte.

Synesios von Kyrene Keine aktuellen Daten verfügbar.

Martin Hose Geboren 1961; Studium der Klassischen Philologie; 1990 Promotion; 1993 Habilitation; seit 1997 Ordinarius für Klassische Philologie an der LMU München; seit 2001 Mitglied der Bayerischen Akademie der Wissenschaften.

Wolfgang Bernard ist Inhaber des Lehrstuhls für Griechische Philologie an der Universität Rostock. Seine Forschungsschwerpunkte sind die Philosophie des Platon und des Aristoteles, einschließlich ihrer Rezeption von Antike bis Neuzeit; antike Literaturtheorie, die attische Tragödie und Homer.

Frank Feder ist seit 2015 leitender wissenschaftlicher Mitarbeiter des Projekts Digitale Gesamtedition und Übersetzung des koptisch-sahidischen Alten Testamentes an der Akademie der Wissenschaften zu Göttingen.

Monika Schuol ist außerplanmäßige Professorin für Alte Geschichte an der Freien Universität Berlin. Ihre Forschungsschwerpunkte sind altorientalische und antike Musikgeschichte, Homer, die römische Kaiserzeit, parthische Geschichte, das antike Judentum, antike Rechtsgeschichte und das Papsttum.

Jetzt bestellen:

https://mohrsiebeck.com/buch/aegyptische-erzaehlungen-oder-ueber-die-vorsehung-9783161564345?no_cache=1 order@mohrsiebeck.com

Telefon: +49 (0)7071-923-17

Telefax: +49(0)7071-51104 